Open Access

\title{
Alcohol consumption among pregnant women in Northern Tanzania 2000-2010: a registry-based study
}

Alexander Blaauw Isaksen ${ }^{1 *}$, Truls Østbye ${ }^{2}$, Blandina Theophil Mmbaga ${ }^{3}$ and Anne Kjersti Daltveit ${ }^{2}$

\begin{abstract}
Background: Alcohol can be harmful to the development of the foetus. In most developed countries, pregnant women are recommended to abstain from alcohol, however in developing countries, women are less likely to receive these recommendations. With respect to pregnant women in Northern Tanzania, this study aims to 1) describe time trends in level of alcohol consumption, 2) assess socio-demographic predictors of alcohol consumption, and 3) describe associations between alcohol consumption and health-related maternal and foetal outcomes.
\end{abstract}

Methods: Data related to 34,090 births between 2000 and 2010 was obtained from the Medical Birth Registry at Kilimanjaro Christian Medical Centre (KCMC) in Moshi, Tanzania and analysed. Poisson regression analysis was used to assess associations between potential risk factors and alcohol consumption, and between alcohol consumption during pregnancy and maternal and foetal health outcomes.

Results: From 2000 to 2010, the proportion of women reporting alcohol consumption during pregnancy decreased from 49.5 to $21.5 \%$. The socio-demographic predictors most strongly related to alcohol consumption were religion (Catholics 53.6\%, Protestants 25.9\%, Muslims $14.8 \%$ ) and tribe (Chaggas $45.2 \%$, Pares 17.3\%, Maasais $6.6 \%$ ). Pregnant women consuming alcohol were more likely to be older, taller, and have higher pre-pregnancy body mass index, and were less likely to present with anaemia $(\mathrm{Hb}<11.0 \mathrm{~g} / \mathrm{dl})$ at last antenatal care (ANC) visit/at admission; adjusted relative risk (ARR) 0.84 (95\% confidence interval 0.79-0.90) for alcohol consumption vs. abstinence. Maternal alcohol consumption during pregnancy was associated with a decreased risk of being small for gestational age (ARR $0.87(0.80-0.94)$ and a decreased risk of gestational age less than 37 weeks (ARR 0.89 (0.81-0.99).

Conclusions: The proportion of pregnant women reporting alcohol consumption decreased by $56.5 \%$ from 2000 to 2010. Alcohol intake was strongly associated with socio-demographic factors. The association between alcohol intake and favourable perinatal outcomes remained significant after maternal factors were adjusted for. Information on diet, lifestyle factors and maternal health might give further insight into this unexpected observation. The proportion of pregnant women consuming alcohol in Northern Tanzania is high, and greater awareness of health outcomes associated with alcohol consumption is advised.

\footnotetext{
* Correspondence: alexander.isaksen@hotmail.com

${ }^{1}$ Faculty of Medicine and Dentistry, University of Bergen, Bergen, Norway

Full list of author information is available at the end of the article
}

\section{Biomed Central}

(c) 2015 Isaksen et al. Open Access This article is distributed under the terms of the Creative Commons Attribution 4.0 International License (http://creativecommons.org/licenses/by/4.0/), which permits unrestricted use, distribution, and reproduction in any medium, provided you give appropriate credit to the original author(s) and the source, provide a link to the Creative Commons license, and indicate if changes were made. The Creative Commons Public Domain Dedication waiver (http://creativecommons.org/publicdomain/zero/1.0/) applies to the data made available in this article, unless otherwise stated. 


\section{Background}

The effect of alcohol consumption on behaviour, health, and society are major public health challenges worldwide [1]. Alcohol consumption during pregnancy generally increases the mother's risk of a wide range of diseases and affects foetal development negatively. Foetal Alcohol Syndrome (FAS) is the most serious condition caused by the consumption of large amounts of alcohol during pregnancy [2]. Binge drinking is particularly damaging to foetal development [3]. Other consequences for children exposed to alcohol during pregnancy include reduced attention span, receptive language and visualmotor skills [4].

Due to the risks associated with alcohol consumption during pregnancy, pregnant women in many developed countries are recommended to abstain from alcohol. However, even in these countries, formal recommendations to abstain from alcohol during pregnancy are relatively recent: In the United States, the Surgeon General first made the recommendation in 2005 [5].

In contrast to developed countries, policies in many developing countries have paid little attention to risks associated with alcohol consumption during pregnancy. While the alcohol-attributable fraction of the total burden of disease in many developing countries, such as Tanzania, is considerably lower than in Europe and the United States [6], the absolute contribution of alcohol to poor health may be even larger [1]. Although the burden of alcohol use during pregnancy has significant consequences, and at least in some African countries alcohol use among pregnant women is high [7], significant variation exist both within and among African countries[8].

This study aims to:

1. Describe time trends in the level of alcohol consumption over a decade among pregnant women in Northern Tanzania.

2. Assess the association of maternal socio-demographic and pre-pregnancy health factors with alcohol consumption during pregnancy.

3. Assess the relationship between alcohol consumption during pregnancy and maternal and foetal health outcomes.

\section{Methods}

\section{Study design and data collection}

This cross sectional study is based on data from the Birth Registry of Kilimanjaro Christian Medical Centre (KCMC) in Moshi, Kilimanjaro Region in Northern Tanzania. The population in Kilimanjaro Region was approximately 1.6 million people in 2012 [9]. KCMC is a referral hospital that receives patients mostly from Kilimanjaro Region (89.6\%), but also from other regions with only lower level hospitals if more advanced treatment is required. The annual number of births at KCMC is approximately 3,200. Since July 2000 all births at KCMC have been registered in the electronic birth registry file. As of November 2010, when the latest data included in this study was recorded, over 34,000 newborns had been included in the registry. The registry is a collaborative project between KCMC, Kilimanjaro Christian Medical University College, and the University of Bergen, Norway.

Mothers who give birth at KCMC are asked to bring their antenatal care (ANC) card (record of ANC visits during pregnancy) to the hospital. If the mother gives oral consent to participate, a project midwife interviews her with a structured questionnaire within 24 hours after delivery. The topics in the questionnaire include: information concerning the child's mother and father, living conditions during pregnancy, the mother's health before and during pregnancy, information concerning the delivery, and on the health of the child/children. Information is also collected from the ANC card.

\section{Study population}

In the analyses of time trends and the relationship between socio-demographic factors/maternal health and alcohol intake during pregnancy, one record per pregnancy was included $(N=33,006)$. In the analyses of the relationship between alcohol intake and perinatal death and low Apgar score, all newborns (including multiple births) were included $(N=33,971)$, but stillbirths were excluded from the analyses of low Apgar score. In the analyses of weight and gestational age, multiple births were excluded as these often are delivered before term and are small for gestational age when compared to singleton standards $(N=29,399)$. Based on a subset of the study population where information on anaemia at last ANC visit or at admission was available, an analysis of anaemia and alcohol consumption during pregnancy was included because anaemia during pregnancy could indicate maternal nutritional status and is a risk factor for poor perinatal outcomes [10]. This information was available for 8,778 pregnancies from 2006 and onwards. In accordance with World Health Organization (WHO) definitions, anaemia was categorized as mild/moderate $(\mathrm{Hb} 7-10.9 \mathrm{~g} / \mathrm{dl})$ or severe $(\mathrm{Hb}<7 \mathrm{~g} / \mathrm{dl})[11]$.

\section{Selection and description of risk factors and outcomes}

In describing time trends and socio-demographic predictors of alcohol use, the main outcome was the mothers' drinking habits during pregnancy, dichotomized into alcohol consumption (yes/no) or according to frequency of alcohol consumption. In the multivariable analysis, only socio-demographic and pre-pregnancy health predictors of alcohol consumption with p-values below 0.05 are presented. Among factors that were not significant 
in the multivariable analysis were marital status and education level of the mother and father.

The association of alcohol with foetal and maternal health outcomes with an occurrence of at least $0.5 \%$ in the registry were considered. Crude and adjusted associations between alcohol consumption and the following health outcomes are presented: maternal anaemia, perinatal mortality, being small for gestational age (below 10th percentile related to gestational age and sex), gestational age below 37 weeks, and low Apgar score 5 minutes after birth. Definitions of health outcomes were selected based on available literature [11-13]. Pregnancy outcomes considered, but not presented due to the non-significant relationship between them and alcohol consumption in the unadjusted analysis, include caesarean section, malformations, head circumference and if the child was transferred to paediatric department postnatally.

\section{Data analysis}

Generalized Linear Models with Poisson regression were used to calculate $p$-values and adjusted relative risks (ARR) with $95 \%$ confidence intervals. In the multivariable models predicting alcohol consumption, only significant factors $(p<0.05)$ were included. In the final model, non-significant factors $(p>0.05)$ were added one by one to assess their significance. All factors were treated as categorical variables in the analysis. All calculations were made with The Statistical Package for Social Science (SPSS) Version 19.0-22.0.

\section{Ethical approval}

The birth registry at KCMC has ethical clearance from the Tanzanian Ministry of Health and National Institute for Medical Research (NIMR), from the Norwegian National Ethics Committee and from the KCM University College. The study is solely based on the KCMC Birth Registry established as a collaborative project between the University of Bergen, Norway and KCMC. The study was initiated in 2011 and approved by birth registry coordinator Rachel Manongi, $\mathrm{KCMC}$, and professor Rolv Terje Lie, University of Bergen, who was the Norwegian project leader for the birth registry project.

\section{Results}

\section{Overall}

$34.1 \%$ of mothers reported alcohol consumption during pregnancy, $19.2 \%$ drank occasionally, $3.9 \%$ drank once a week, $10.1 \%$ drank more than once a week and $1.0 \%$ drank alcohol daily.

\section{Trends}

The percentage of mothers who reported alcohol consumption during pregnancy declined from $49.5 \%$ in 2000 to $21.5 \%$ in $2010(p<0.001)$ (Fig. 1). A decline was observed in all socio-demographic groups. It was most pronounced in mothers aged 17 or younger, where the decrease was from $29.4 \%$ in 2000 to $6.4 \%$ in 2010 . In the oldest mothers, the decrease was from $55.7 \%$ to $33.8 \%$ during the same time period. Frequency of drinking decreased during the observation period: for example, the proportion of women who drank daily declined from $1.4 \%$ in 2000 to $0.1 \%$ in $2010(p<0.001)$.

\section{Socio-demographic and pre-pregnancy health predictors of alcohol consumption}

Alcohol consumption varied with most socio-demographic variables (Table 1). Alcohol consumption increased with maternal age, from $17.4 \%$ among mothers aged 17 or younger to $42.5 \%$ among mothers aged 36 years or older. In terms of birth order, $26.7 \%$ of nulliparous women reported to drink during pregnancy compared to $41.1 \%$ of mothers with 3 or more previous pregnancies. $45.2 \%$ of women of the Chagga tribe reported alcohol consumption, which was higher than what women of the Pare tribe (17.3\%), the Maasai tribe (6.6\%) and other tribes (21.8\%) reported. Compared to Protestant and Muslim women, frequency of alcohol consumption during pregnancy was highest amongst Catholic women. Overweight and obese women, tall women and those with positive HIV status were more likely to consume alcohol during pregnancy compared to underweight women and those with a normal weight, short women and those with negative HIV status.

\section{Alcohol and anaemia}

In the multivariable analyses, the ARR of anaemia $(\mathrm{Hb}<11.0 \mathrm{~g} / \mathrm{dL})$ was $0.84(0.79-0.90)$ for those who consumed alcohol compared to those who abstained from alcohol. Corresponding numbers for severe anaemia and mild/moderate anaemia were $0.74(0.58-0.95)$ and $0.86(0.80-0.93)$, respectively (Table 2$)$.

\section{Foetal outcomes}

Mothers who reported alcohol consumption during pregnancy were less likely to have babies small for gestational age (below 10th percentile when related to gestational age and sex) and to deliver before term ( $<37$ weeks) compared with mothers who abstained from alcohol. ARRs were $0.87(0.80-0.94)$ for delivering a baby that was small for gestational age and $0.89(0.81-0.99)$ for preterm birth (Table 3), respectively.

\section{Discussion}

In this registry-based study of 34,090 deliveries in Northern Tanzania from 2000 to 2010, 34.1\% of pregnant women reported alcohol consumption during pregnancy, with a decline from $49.5 \%$ in 2000 to $21.5 \%$ in 2010. Alcohol consumption was associated with socio-demographic predictors including tribe, age of the mother and father, 


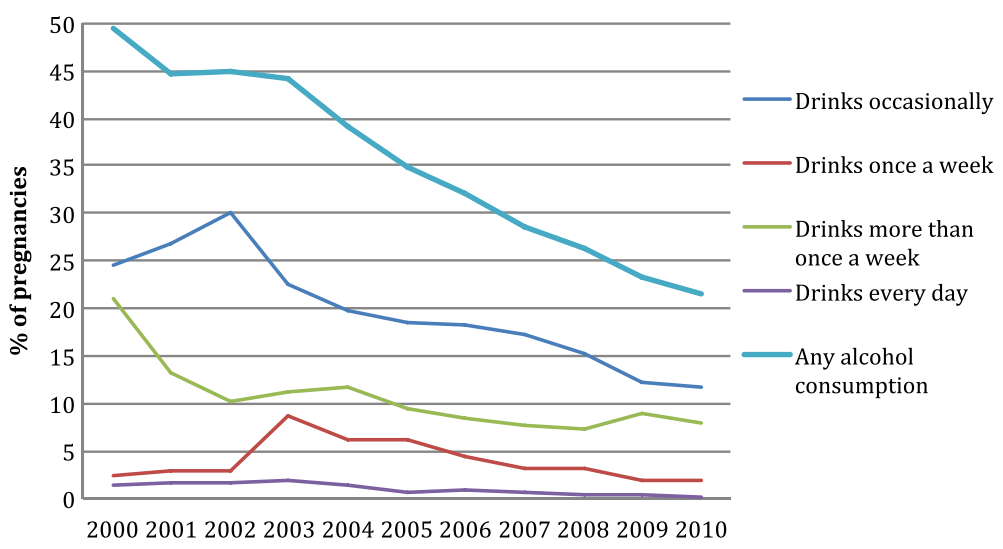

Fig. 1 Time trends in alcohol consumption overall and by amount of alcohol consumed during pregnancy

religion and the mother's pre-pregnancy body mass index. In general, and contrary to expectations, women who reported alcohol consumption had more favourable pregnancy outcomes than women who abstained from alcohol. These associations were attenuated in the adjusted analysis, although still significant for the outcomes small for gestational age and low gestational age. Similarly, in the sub-study of women with known haemoglobin status (26.5\% of the deliveries), those who consumed alcohol had a lower risk of presenting with anaemia at last ANC visit/at admission.

\section{Drinking pattern and time trends}

The proportion of pregnant women in this study who consumed alcohol is higher than what is reported in developed countries. In an American survey from 2006 to 2010, $7.6 \%$ of pregnant women reported alcohol consumption [14]. The proportion of women who abstained from alcohol (65.9\%) in our study is consistent with the WHO's estimates of lifetime abstainers in Sub-Saharan Africa (65.2 \%) [1]. However, regional variations in consumption may be large, and the Kilimanjaro Region has one of the highest reported levels of alcohol consumption per capita in Tanzania [15]. Cultural habits and lack of knowledge about the effect of alcohol on maternal and perinatal health are potential explanations for the high proportion of pregnant women who consume alcohol. According to project midwives at KCMC [personal communication], pregnant women in their district do not routinely receive information about the potentially damaging effects of alcohol on perinatal health. It is therefore likely that during pregnancy, women proceed with drinking the same level of alcohol consumption as before pregnancy, with the exception of women who changed their eating and drinking habits due to nausea.

Notably, from 2000 to 2010, there was a decline in reported alcohol consumption during pregnancy from $49.5 \%$ to $21.5 \%$. A decline was observed in all socio- demographic groups, although the decline was strongest in younger women. The overall trend was slightly attenuated after adjustment for socio-demographic factors, indicating that a part of the decline was due to changes in the distribution of socio-demographic factors. During ANC visits, the availability of information about the consequences of alcohol consumption on maternal and perinatal outcomes is insufficient; therefore, the observed decline in alcohol consumption is not likely due to knowledge gained during ANC visits. However, a possible explanation for the decline in consumption could still be increased knowledge of the effects of alcohol in the general community. An alternative explanation could be a decrease in financial resources; this could explain the decrease in consumption among the youngest mothers, as it often is the youngest who have the smallest financial resources. Despite growth in the Tanzanian GNP, the poverty rate has remained stable since 2001 at about $30 \%$ of the population [16]. Finally, a changing drinking culture may be another explanation for the decrease in alcohol consumption. In conclusion, a combination of cultural, knowledge-based and economic reasons offer possible explanations for the decline in alcohol consumption among pregnant women in Northern Tanzania.

\section{Socio-demographic factors}

Religion and tribe were the most important predictors of alcohol consumption. This may be due to cultural differences, economy, or traditional food and beverages unique to the area. In Tanzania, where home brew represent about $90 \%$ of the alcohol consumed [17], traditions play a strong role in alcohol consumption. The Chagga tribe are traditionally farmers growing bananas and other crops. Their traditional brew, mbege, is made of bananas and finger millet flowers. Compared to the Chaggas, the Maasai tribe who traditionally are nomads with cattle does not have a strong drinking culture, because traditionally, they did not grow any crops that could be used for brewing. In 
Table 1 Socio-demographic and pre-pregnancy health related predictors of alcohol consumption among pregnancies in Northern Tanzania

\begin{tabular}{|c|c|c|c|c|c|c|}
\hline \multirow[b]{3}{*}{ Variables } & \multirow{3}{*}{$\begin{array}{l}\% \text { of } \\
\text { pregnancies }\end{array}$} & \multicolumn{5}{|c|}{ Mothers who drank alcohol during the pregnancy } \\
\hline & & \multirow[t]{2}{*}{$\%$ drinking alcohol } & \multicolumn{2}{|l|}{ Univariate analysis } & \multicolumn{2}{|c|}{ Multivariable model $^{(a)}$} \\
\hline & & & RR $(95 \% \mathrm{Cl})$ & $p$-value & ARR (95 \% Cl) & $p$-value \\
\hline Total $(n=33006)^{(b)}$ & 100.0 & 34.1 & & & & \\
\hline Mother's age in years $(n=32985)$ & & & & $<0.001$ & & 0.001 \\
\hline 17 or younger & 2.6 & 17.4 & $0.41(0.35-0.48)$ & & $0.83(0.66-1.03)$ & \\
\hline $18-25$ & 38.9 & 28.3 & $0.67(0.64-0.70)$ & & $0.93(0.86-1.00)$ & \\
\hline $26-35$ & 48.2 & 37.9 & $0.89(0.85-0.93)$ & & $1.02(0.97-1.08)$ & \\
\hline 36 or older & 10.3 & 42.5 & 1.00 & & 1.00 & \\
\hline Number of previous pregnancies $(n=32029)$ & & & & $<0.001$ & & $<0.001$ \\
\hline 0 & 37.0 & 26.7 & $0.65(0.62-0.68)$ & & $0.82(0.77-0.87)$ & \\
\hline 1 & 26.4 & 36.2 & $0.88(0.84-0.92)$ & & $1.00(0.95-1.05)$ & \\
\hline 2 & 17.3 & 41.8 & $1.02(0.97-1.06)$ & & $1.09(1.04-1.15)$ & \\
\hline 3 or more & 19.3 & 41.1 & 1.00 & & 1.00 & \\
\hline Mother's tribe $(n=32961)$ & & & & $<0.001$ & & $<0.001$ \\
\hline Chagga & 55.8 & 45.2 & $2.07(1.99-2.16)$ & & $1.34(1.27-1.41)$ & \\
\hline Pare & 12.6 & 17.3 & $0.79(0.74-0.86)$ & & $0.92(0.84-1.01)$ & \\
\hline Maasai & 1.0 & 6.6 & $0.31(0.21-0.45)$ & & $0.88(0.57-1.35)$ & \\
\hline Other & 30.6 & 21.8 & 1.00 & & 1.00 & \\
\hline Mother's religion $(n=32783)$ & & & & $<0.001$ & & $<0.001$ \\
\hline Catholic & 38.6 & 53.6 & $3.62(3.41-3.84)$ & & $2.91(2.69-3.14)$ & \\
\hline Protestant & 40.0 & 25.9 & $1.75(1.64-1.87)$ & & $1.59(1.47-1.72)$ & \\
\hline Muslim & 21.4 & 14.8 & 1.00 & & 1.00 & \\
\hline Mother's Body Mass Index before pregnancy $(n=25417)$ & & & & $<0.001$ & & $<0.001$ \\
\hline$<18.5$ Underweight & 5.2 & 23.8 & $0.58(0.50-0.67)$ & & $0.71(0.62-0.82)$ & \\
\hline 18.5 - 24.9 Normal weight & 56.8 & 33.7 & $0.82(0.73-0.91)$ & & $0.86(0.77-0.96)$ & \\
\hline 25.0 - 29.9 Overweight & 26.9 & 41.5 & $1.01(0.90-1.13)$ & & $0.95(0.85-1.06)$ & \\
\hline 30.0 - 34.9 Obese Class 1 (Moderately Obese) & 9.3 & 44.3 & $1.07(0.95-1.21)$ & & $0.97(0.87-1.09)$ & \\
\hline$\geq 35.0$ Obese Class 2 (Severely Obese) & 1.8 & 41.3 & 1.00 & & 1.00 & \\
\hline Mother's height $(n=29314)$ & & & & $<0.001$ & & 0.001 \\
\hline$<150 \mathrm{~cm}$ & 5.5 & 26.7 & $0.67(0.60-0.73)$ & & $0.81(0.73-0.90)$ & \\
\hline $150-159 \mathrm{~cm}$ & 41.3 & 33.8 & $0.84(0.79-0.89)$ & & $0.92(0.86-0.97)$ & \\
\hline $160-169 \mathrm{~cm}$ & 45.9 & 36.8 & $0.92(0.87-0.97)$ & & $0.91(0.86-0.97)$ & \\
\hline$\geq 170 \mathrm{~cm}$ & 7.3 & 40.2 & 1.00 & & 1.00 & \\
\hline Current residence $(n=32913)$ & & & & $<0.001$ & & 0.001 \\
\hline Urban area & 52.2 & 34.4 & $1.00(0.97-1.04)$ & & $1.07(1.03-1.11)$ & \\
\hline Semiurban area & 4.8 & 28.5 & $0.83(0.77-0.90)$ & & $1.01(0.92-1.11)$ & \\
\hline Rural area & 43.0 & 34.3 & 1.00 & & 1.00 & \\
\hline HIV status $(n=33006)$ & & & & $<0.001$ & & $<0.001$ \\
\hline Negative & 59.4 & 28.9 & $0.69(0.67-0.71)$ & & $0.91(0.87-0.95)$ & \\
\hline Positive & 3.9 & 39.3 & $0.94(0.87-1.00)$ & & $1.11(1.01-1.21)$ & \\
\hline Unknown & 36.7 & 42.0 & 1.00 & & 1.00 & \\
\hline
\end{tabular}


Table 1 Socio-demographic and pre-pregnancy health related predictors of alcohol consumption among pregnancies in Northern Tanzania (Continued)

\begin{tabular}{|c|c|c|c|c|c|c|}
\hline Father's age $(n=32745)$ & & & & $<0.001$ & & $<0.001$ \\
\hline 25 or younger & 15.1 & 25.7 & $0.60(0.56-0.65)$ & & $0.82(0.74-0.91)$ & \\
\hline $26-35$ & 55.2 & 33.0 & $0.77(0.73-0.83)$ & & $0.85(0.79-0.92)$ & \\
\hline $36-45$ & 25.6 & 40.5 & $0.95(0.89-1.02)$ & & $0.93(0.86-1.00)$ & \\
\hline 46 or older & 4.2 & 42.6 & 1.00 & & 1.00 & \\
\hline Father's tribe $(n=32835)$ & & & & $<0.001$ & & $<0.001$ \\
\hline Chagga & 50.3 & 45.3 & $1.85(1.79-1.92)$ & & $1.24(1.19-1.30)$ & \\
\hline Pare & 12.5 & 19.2 & $0.78(0.73-0.84)$ & & $0.94(0.87-1.03)$ & \\
\hline Maasai & 1.4 & 13.6 & $0.56(0.44-0.70)$ & & $1.00(0.78-1.30)$ & \\
\hline Other & 35.8 & 24.5 & 1.00 & & 1.00 & \\
\hline Year $(n=33006)$ & & & & $<0.001$ & & $<0.001$ \\
\hline 2000 & 4.8 & 49.5 & $2.30(2.12-2.49)$ & & $1.88(1.68-2.11)$ & \\
\hline 2001 & 10.1 & 44.7 & $2.08(1.93-2.24)$ & & $1.86(1.68-2.07)$ & \\
\hline 2002 & 9.1 & 44.9 & $2.09(1.94-2.25)$ & & $1.86(1.68-2.07)$ & \\
\hline 2003 & 8.1 & 44.2 & $2.06(1.90-2.22)$ & & $1.72(1.55-1.91)$ & \\
\hline 2004 & 8.5 & 39.1 & $1.82(1.68-1.97)$ & & $1.58(1.42-1.76)$ & \\
\hline 2005 & 8.6 & 34.9 & $1.62(1.49-1.76)$ & & $1.49(1.34-1.66)$ & \\
\hline 2006 & 8.9 & 32.0 & $1.49(1.37-1.62)$ & & $1.46(1.31-1.62)$ & \\
\hline 2007 & 9.8 & 28.5 & $1.33(1.22-1.44)$ & & $1.25(1.12-1.40)$ & \\
\hline 2008 & 10.9 & 26.2 & $1.22(1.12-1.33)$ & & $1.20(1.08-1.34)$ & \\
\hline 2009 & 10.8 & 23.3 & $1.08(0.99-1.18)$ & & $1.02(0.92-1.15)$ & \\
\hline 2010 & 10.4 & 21.5 & 1.00 & & 1.00 & \\
\hline
\end{tabular}

(a) In the multivariable analyses all predictors have been adjusted for mother's age, mother's occupation, mother's tribe, mother's religion, mother's body mass index, mother's height, previous pregnancies, mother's current residence, mother's childhood residence, father's age, father's tribe, year of delivery, drinking water source, boiling of drinking water, mother's age at marriage and mother's HIV-status

(b) For all the predictors one data entry per pregnancy has been included

addition, Maasai women traditionally were not allowed to drink alcohol before a certain age, at which point they drank only on specific occasions. These differences may explain why Chagga women were almost 7 times more likely to drink alcohol as Maasai women during pregnancy.

The results show a strong link between religion and alcohol consumption. Muslims, who are supposed to abstain from alcohol, have the lowest alcohol consumption rates among religious groups. The differences between the two included Christian groups (Catholics and Protestants) may be explained by different views on alcohol, as many Protestant churches, especially Evangelical churches, have been a part of the Temperance or Teetotalism movement [18], while most parts of the Catholic Church have not [19].

\section{Foetal and maternal outcomes \\ Overall}

Mothers who consumed alcohol during pregnancy had newborns with lower risks of perinatal death, being small for gestational age, low gestational age and low Apgar score 5 minutes after birth in the crude models. In the multivariable models, the lower risks of being small for gestational age and low gestational age for children born to mothers who consumed alcohol during pregnancy remained statistically significant. Previous studies have shown various results of low/moderate alcohol consumption during pregnancy, with some studies reporting protective associations with respect to stillbirth, intrauterine growth restriction, low birth weight, and preterm delivery [20-23]. In 2007 a metaanalysis of data from mainly developed countries was inconclusive about maternal alcohol consumption's effect on foetal health [24]. Hence, unmeasured confounders, such as beneficial nutrients in traditional alcoholic beverages, or even a positive effect of alcohol per se are possible explanations for these findings.

\section{Diet and maternal health}

Although the results are adjusted for maternal height, weight and many socio-demographic factors, there may still be unmeasued confounding variables. In many developing countries, the most important 
Table 2 Associations between pregnant women's alcohol consumption and maternal anaemia in Northern Tanzania 2006-2010

\begin{tabular}{|c|c|c|c|c|c|c|}
\hline \multirow[b]{2}{*}{ Variables } & \multirow{2}{*}{$\begin{array}{l}\% \text { of } \\
\text { pregnancies }\end{array}$} & \multirow{2}{*}{$\begin{array}{l}\% \text { of pregnancies } \\
\text { associated with } \\
\text { anaemia }\end{array}$} & \multicolumn{2}{|l|}{ Univariate analysis } & \multicolumn{2}{|c|}{ Multivariable model $^{(\mathrm{a})}$} \\
\hline & & & $\mathrm{RR}(95 \% \mathrm{Cl})$ & $p$-value & ARR $(95 \% \mathrm{Cl})$ & $p$-value \\
\hline \multicolumn{7}{|c|}{ Anaemia during pregnancy $(\mathrm{Hb}<11.0 \mathrm{~g} / \mathrm{dL})(n=8778)^{(\mathrm{b})}$} \\
\hline Drinks alcohol & 26.7 & 46.5 & $0.81(0.77-0.85)$ & $<0.001$ & $0.84(0.79-0.90)$ & $<0.001$ \\
\hline Drinks alcohol every day & 0.4 & 43.6 & $0.76(0.53-1.08)$ & 0.126 & $0.82(0.49-1.36)$ & 0.439 \\
\hline Drinks alcohol more than once a week & 7.4 & 41.6 & $0.72(0.66-0.79)$ & $<0.001$ & $0.77(0.68-0.87)$ & $<0.001$ \\
\hline Drinks alcohol once a week & 2.9 & 44.0 & $0.77(0.66-0.88)$ & $<0.001$ & $0.78(0.64-0.95)$ & 0.012 \\
\hline Drinks occasionally & 16.0 & 49.2 & $0.85(0.81-0.90)$ & $<0.001$ & $0.88(0.82-0.95)$ & 0.002 \\
\hline Abstains from alcohol & 73.3 & 57.6 & 1.00 & & 1.00 & \\
\hline \multicolumn{7}{|c|}{ Severe anaemia during pregnancy $(\mathrm{Hb}<7.0 \mathrm{~g} / \mathrm{dL})(n=8778)^{(\mathrm{b})}$} \\
\hline Drinks alcohol & 26.7 & 6.1 & $0.75(0.63-0.90)$ & 0.002 & $0.74(0.58-0.95)$ & 0.016 \\
\hline Drinks alcohol every day & 0.4 & 12.8 & $1.58(0.69-3.60)$ & 0.276 & $1.12(0.44-2.86)$ & 0.811 \\
\hline Drinks alcohol more than once a week & 7.4 & 6.0 & $0.74(0.54-1.02)$ & 0.062 & $0.51(0.32-0.80)$ & 0.003 \\
\hline Drinks alcohol once a week & 2.9 & 6.3 & $0.78(0.48-1.27)$ & 0.318 & $0.70(0.34-1.41)$ & 0.318 \\
\hline Drinks occasionally & 16.0 & 5.9 & $0.73(0.58-0.91)$ & 0.006 & $0.87(0.66-1.16)$ & 0.353 \\
\hline Abstains from alcohol & 73.3 & 8.1 & 1.00 & & 1.00 & \\
\hline \multicolumn{7}{|c|}{ Mild/moderate anaemia during pregnancy $(\mathrm{Hb} 7.0-10.9 \mathrm{~g} / \mathrm{dL})(n=8778)^{(\mathrm{b})}$} \\
\hline Drinks alcohol & 26.7 & 40.4 & $0.82(0.77-0.86)$ & $<0.001$ & $0.86(0.80-0.93)$ & $<0.001$ \\
\hline Drinks alcohol every day & 0.4 & 30.8 & $0.62(0.39-1.00)$ & 0.048 & $0.70(0.35-1.39)$ & 0.310 \\
\hline Drinks alcohol more than once a week & 7.4 & 35.6 & $0.72(0.65-0.80)$ & $<0.001$ & $0.82(0.72-0.94)$ & 0.004 \\
\hline Drinks alcohol once a week & 2.9 & 37.7 & $0.76(0.65-0.89)$ & 0.001 & $0.79(0.64-0.98)$ & 0.034 \\
\hline Drinks occasionally & 16.0 & 43.3 & $0.88(0.82-0.93)$ & $<0.001$ & $0.89(0.81-0.97)$ & 0.007 \\
\hline Abstains from alcohol & 73.3 & 49.5 & 1.00 & & 1.00 & \\
\hline
\end{tabular}

(a) In the multivariable analyses the associations with alcohol have for all the outcomes been adjusted for the following predictors: mother's age, mother's occupation, mother's tribe, mother's religion, mother's body mass index, mother's height, previous pregnancies, mother's current residence, mother's childhood residence, father's age, father's tribe, year of delivery, drinking water source, boiling of drinking water, mother's age at marriage and mother's HIV-status

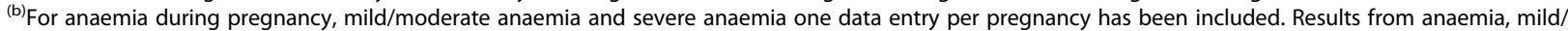
moderate anaemia and severe anaemia are based on 8778 pregnancies registered from 2006 and onwards

predictors of health are income, education and occupation [25]. Data used for this study contains no information on personal income. Women who are able to purchase alcohol may have more economic resources, and consequently, more and better food. This would positively affect their daily caloric intake, which is the most important nutritional factor determining birth weight [26]. In addition there may be a "healthy drinker" effect where mothers with a poor obstetric history choose to abstain from alcohol [24].

\section{Nutrients in traditional brew}

Another possible explanation for why mothers who consumed alcohol during pregnancy had healthier newborns is that there are substances in traditional alcoholic beverages that are beneficial for the foetus. In Tanzania, most alcohol consumed is from local brews, but the main ingredients differ from tribe to tribe. The local brew of the Chagga tribe, mbege, is rich in nutrients and traditionally therefore considered healthy. There may be vitamins and minerals in local brews that are beneficial to the foetus, and consumers of traditional beer are reported to have higher folate and vitamine B12 levels [27]. A recent review, however, showed that folate supplementation did not significantly reduce perinatal death, preterm birth or low birth weight [28]. In our study, alcohol was not associated with perinatal death in Chaggas $(R R=0.98)$ whereas relative risk was 0.83 for other tribes. This may indicate that the effect of alcohol is not related to nutrients in the Chagga brew.

\section{Iron and anaemia}

Pregnant women who consumed alcohol were less likely to present with anaemia at last ANC/at delivery. One explanation for this may be that traditional Tanzanian brews are often cooked in iron pots before fermentation [29]. In contrast, commercially prepared beer lacks iron. Inadequate iron intake is a cause of anaemia and several countries advise pregnant women to take daily iron supplements [30]. Surveys have shown that if the mother takes iron supplements during pregnancy, the baby will 
Table 3 Associations between mothers' alcohol consumption and foetal health outcomes in Northern Tanzania 2000-2010

\begin{tabular}{|c|c|c|c|c|c|c|}
\hline \multirow[b]{2}{*}{ Variables } & \multirow{2}{*}{$\begin{array}{l}\% \text { of } \\
\text { births }\end{array}$} & \multirow{2}{*}{$\begin{array}{l}\%(n) \text { of } \\
\text { births with } \\
\text { outcome }\end{array}$} & \multicolumn{2}{|l|}{ Univariate analysis } & \multicolumn{2}{|c|}{ Multivariable model $^{(\mathrm{a})}$} \\
\hline & & & $\mathrm{RR}(95 \% \mathrm{Cl})$ & $p$-value & $\operatorname{ARR}(95 \% \mathrm{Cl})$ & $p$-value \\
\hline \multicolumn{7}{|l|}{ Perinatal death $(n=33971)^{(b)}$} \\
\hline Drinks alcohol & 34.1 & $5.2(606)$ & $0.83(0.76-0.91)$ & $<0.001$ & $0.93(0.81-1.07)$ & 0.288 \\
\hline Drinks alcohol every day & 1.0 & $3.3(11)$ & $0.53(0.30-0.95)$ & 0.032 & $0.40(0.17-0.96)$ & 0.041 \\
\hline Drinks alcohol more than once a week & 10.1 & $4.6(157)$ & $0.72(0.62-0.85)$ & $<0.001$ & $0.81(0.64-1.01)$ & 0.064 \\
\hline Drinks alcohol once a week & 3.8 & $5.1(66)$ & $0.80(0.63-1.02)$ & 0.073 & $1.05(0.77-1.44)$ & 0.743 \\
\hline Drinks occasionally & 19.2 & $5.7(372)$ & $0.90(0.81-1.01)$ & 0.071 & $0.99(0.85-1.16)$ & 0.930 \\
\hline Abstains from alcohol & 65.9 & $6.3(1414)$ & 1.00 & & 1.00 & \\
\hline \multicolumn{7}{|c|}{ Small for gestational age (below 10th percentile related to gestational age and sex $\left.{ }^{(d)}\right)(n=27065)^{(c)}$} \\
\hline Drinks alcohol & 34.4 & $14.0(1305)$ & $0.81(0.76-0.86)$ & $<0.001$ & $0.87(0.80-0.94)$ & 0.001 \\
\hline Drinks alcohol every day & 1.0 & $13.8(36)$ & $0.80(0.59-1.08)$ & 0.142 & $0.81(0.54-1.22)$ & 0.316 \\
\hline Drinks alcohol more than once a week & 10.0 & $13.5(367)$ & $0.78(0.71-0.86)$ & $<0.001$ & $0.88(0.77-1.00)$ & 0.052 \\
\hline Drinks alcohol once a week & 4.0 & $14.2(153)$ & $0.82(0.70-0.95)$ & 0.009 & $0.80(0.65-0.98)$ & 0.034 \\
\hline Drinks occasionally & 19.4 & $14.3(749)$ & $0.82(0.77-0.89)$ & $<0.001$ & $0.88(0.79-0.97)$ & 0.007 \\
\hline Abstains from alcohol & 65.6 & $17.3(3079)$ & 1.00 & & 1.00 & \\
\hline \multicolumn{7}{|l|}{ Low gestational age $<37$ weeks $(n=29399)^{(\mathrm{c})}$} \\
\hline Drinks alcohol & 34.4 & $10.5(1062)$ & $0.85(0.79-0.91)$ & $<0.001$ & $0.89(0.81-0.99)$ & 0.024 \\
\hline Drinks alcohol every day & 1.0 & $11.7(33)$ & $0.95(0.69-1.31)$ & 0.735 & $0.93(0.61-1.41)$ & 0.723 \\
\hline Drinks alcohol more than once a week & 10.1 & $10.1(301)$ & $0.82(0.73-0.92)$ & $<0.001$ & $0.90(0.77-1.05)$ & 0.170 \\
\hline Drinks alcohol once a week & 4.0 & $10.5(123)$ & $0.85(0.71-1.00)$ & 0.055 & $0.91(0.72-1.15)$ & 0.450 \\
\hline Drinks occasionally & 19.4 & $10.6(605)$ & $0.86(0.79-0.93)$ & $<0.001$ & $0.88(0.78-1.00)$ & 0.043 \\
\hline Abstains from alcohol & 65.6 & $12.4(2394)$ & 1.00 & & 1.00 & \\
\hline \multicolumn{7}{|c|}{ Low Apgar score 5 min after birth (Apgar score $<7)(n=32363)^{(b)}$} \\
\hline Drinks alcohol & 34.2 & $2.7(304)$ & $0.87(0.76-0.99)$ & 0.039 & $1.12(0.92-1.36)$ & 0.249 \\
\hline Drinks alcohol every day & 1.0 & $2.2(7)$ & $0.70(0.34-1.47)$ & 0.348 & $0.48(0.12-1.94)$ & 0.300 \\
\hline Drinks alcohol more than once a week & 10.2 & $2.6(85)$ & $0.82(0.65-1.02)$ & 0.076 & $1.28(0.95-1.73)$ & 0.104 \\
\hline Drinks alcohol once a week & 3.8 & $2.3(29)$ & $0.74(0.51-1.06)$ & 0.103 & $1.23(0.78-1.95)$ & 0.371 \\
\hline Drinks occasionally & 19.2 & $2.9(183)$ & $0.93(0.79-1.09)$ & 0.384 & $1.10(0.88-1.38)$ & 0.386 \\
\hline Abstains from alcohol & 65.8 & $3.2(673)$ & 1.00 & & 1.00 & \\
\hline
\end{tabular}

(a) In the multivariable analyses the associations with alcohol have for all the outcomes been adjusted for the following predictors: mother's age, mother's occupation, mother's tribe, mother's religion, mother's body mass index, mother's height, previous pregnancies, mother's current residence, mother's childhood residence, father's age, father's tribe, year of delivery, drinking water source, boiling of drinking water, mother's age at marriage and mother's HIV-status

${ }^{(b)}$ Analyses of perinatal death and low Apgar score $5 \mathrm{~min}$ after birth includes all births including twins and triplets. Low Apgar score does not include stillbirths

(c) Analyses of small for gestational age and low gestational age include singleton births only

(d) Limits for 10th percentile related to gestational age and sex are based on Villar et al., 2014

have a higher birth weight and a lower risk of being born preterm [31].

\section{Limitations}

The registry file used for these analyses pertained to deliveries at $\mathrm{KCMC}$, where patients may have demographic characteristics that are unique from the rest of the Kilimanjaro Region population. Treatment at KCMC may differ from home deliveries and less equipped hospitals. Hemoglobin was only recorded after 2006. The registry is based on self-reports, which may be unreliable. For example, alcohol consumption is commonly overestimated or underestimated [32] based on local culture and its acceptance of alcohol. In terms of alcohol, only information on consumption frequency exists, not the absolute amounts consumed. This makes it difficult to compare our results to other surveys and predictions of dose-response relationships may become unreliable.

The registry does not contain detailed information on some important aspects of pregnant womens' health status, such as nutrition level. Compared to developed countries, nutrition in Tanzania is less varied and malnutrition is far more common. As alcohol consumption might be an indicator of the mothers' nutrition level, 
nutritional status as a cause of the observed associations cannot be ruled out.

Another limitation is that the birth registry does not collect data on newborn conditions that are not evident at birth. It is therefore not possible to evaluate whether mothers who consumed alcohol during pregnancy have healthier babies in the long term. As alcohol is estimated to be responsible for only $1 \%$ of low birth weight cases in most African countries [6], it is difficult to demonstrate the effect of alcohol without monitoring more prominent causes of low birth weight and of being small for gestational age.

\section{Conclusions}

From 2000 to 2010, the percentage of women who reported alcohol consumption during pregnancy decreased from $49.5 \%$ to $21.5 \%$. The reason for this decline remains unclear, but a combination of explanations is likely, and include cultural, knowledge-based and economic factors, such as poor economy among young mothers.

The socio-demographic factors that were most strongly related to alcohol consumption were religion and tribe. Mothers with a positive HIV-status drank alcohol more frequently than those with a negative HIVstatus. Alcohol intake may interfere with the effect of HIV treatment.

Alcohol was associated with better birth outcomes, however, it is unlikely that alcohol consumption in itself can explain these findings. Better nutrition and health among mothers who reported alcohol consumption are more likely reasons for these associations, but our data do not allow for a detailed analysis that would fully account for these factors.

Further studies are needed to assess whether knowledge about the effects of alcohol in Tanzania is changing, and to assess long term effects of alcohol during pregnancy.

\section{Competing interests}

The authors declare that they have no competing interests.

\section{Authors' contributions}

ABI carried out the statistical analysis and drafted the manuscript. AKD, TØ and BTM reviewed the analyses and the manuscript critically. All authors read and approved the final manuscript.

\footnotetext{
Acknowledgements

The authors thank the staff at KCMC and the Birth Registry for collecting and registrating the data. In particular, we would like to thank Dr. Rachel Manongi, Michael Mahande and Paulina Calist for assisting in different ways, Prof. Rolv Terje Lie for valuable contributions in the writing process, and Kaitlin Saxton for helpful editing. The authors also thank the Norwegian Cooperation Programme for Development, Research and Higher Education (NUFU) for funds to support and maintain the registry. Last but not least; A special thanks goes to all the mothers and their babies who participated in the data collection.
}

\section{Author details}

${ }^{1}$ Faculty of Medicine and Dentistry, University of Bergen, Bergen, Norway. ${ }^{2}$ Department of Global Public Health and Primary Care, University of Bergen, Bergen, Norway. ${ }^{3}$ Department of Paediatrics and Child Health, Kilimanjaro Christian Medical Centre and Kilimanjaro Christian Medical University College, Moshi, Tanzania.

Received: 28 October 2014 Accepted: 21 August 2015

Published online: 03 September 2015

\section{References}

1. Global Status Report on Alcohol and Health. Geneva, Switzerland: World Health Organization; 2011.

2. Hoyme HE, May PA, Kalberg WO, Kodituwakku P, Gossage JP, Trujillo PM, et al. A practical clinical approach to diagnosis of fetal alcohol spectrum disorders clarification of the Institute of Medicine Criteria. Pediatrics. 1996;2005(115):39-47.

3. Maier SE, West JR. Drinking patterns and alcohol-related birth defects. Alcohol Res Health. 2001;25:168-74.

4. Korkman M, Autti-Rämö I, Koivulehto H, Granström ML. Neuropsychological effects at early school age of fetal alcohol exposure of varying duration. Child Neuropsychol. 1998;4:199-212.

5. U.S. Surgeon General releases advisory on alcohol use in pregnancy [https://wayback.archive-it.org/3926/20140421162517/http:// www.surgeongeneral.gov/news/2005/02/sg02222005.html\#]Accessed 24 August 2015.

6. Rehm J, Room R, Graham K, Monteiro M, Gmel G, Sempos CT. The relationship of average volume of alcohol consumption and patterns of drinking to burden of disease: an overview. Addiction. 2003;98:1209-28.

7. Williams PP, Jordaan E, Mathews C, Lombard C, Parry CD. Alcohol and Other Drug Use during Pregnancy among Women Attending Midwife Obstetric Units in the Cape Metropole, South Africa. Adv Prev Med. 2014;2014:871427.

8. Culley CL, Ramsey TD, Mugyenyi G, Kiwanuka GN, Ngonzi J, MacLeod S, et al. Alcohol exposure among pregnant women in Sub-Saharan Africa: a systematic review. J Popul Ther Clin Pharmacol. 2013;20:321-33.

9. 2012 Tanzania Population and Housing Census. Dar es Salaam, Tanzania: National Bureau of Statistics Tanzania; 2013.

10. Msuya SE, Hussein TH, Uriyo J, Sam NE, Stray-Pedersen B. Anaemia among pregnant women in northern Tanzania: prevalence, risk factors and effect on perinatal outcomes. Tanzan J Health Res. 2011;13:33-9.

11. Iron Deficiency Anaemia: Assessment, Prevention and Control - A Guide for Programme Managers. Geneva, Switzerland: World Health Organization; 2001:49-50.

12. Villar J, Ismail LC, Victora CG, Ohuma EO, Bertino E, Altman DG, et al. International standards for newborn weight, length, and head circumference by gestational age and sex: the Newborn Cross-Sectional Study of the INTERGROWTH - 21st Project. Lancet. 2014;384:857-68.

13. Born Too Soon: The Global Action Report on Premature Birth. Geneva, Switzerland: World Health Organization, March of Dimes, The Partnership for Maternal, Newborn and Child Health, Save the Children; 2012.

14. Centers for Disease Control and Prevention. Alcohol use and binge drinking among women of childbearing age - United States, 2006-2010. Morb Mortal Wkly Rep. 2012;61:534-8.

15. Henricson C: Alcohol Consumption in the Kilimanjaro Area. In: Kilonzo GP, Pitkänen YT, editors. Pombe: Report of Alcohol Research Project in Tanzania 1988-90. Helsinki, Finland: University of Helsinki; 1992.

16. Morisset J: Tanzania Economic Update - Spreading the Wings: From Growth to Shared Prosperity. Washington DC, USA: The World Bank Group, Africa Region Poverty Reduction \& Economic Management; 2012

17. Global Status Report on Alcohol 1999, Country Profiles: African Region. Geneva, Switzerland: World Health Organization; 1999

18. Kobler J. Ardent Spirits: The Rise and Fall of Prohibition. Cambridge, MA, USA: Da Capo Press; 1993.

19. Engs RC. Protestants and Catholics: Drunken Barbarians and Mellow Romans? Bloomington, IN, USA: White Paper; 2000.

20. Marbury MC, Linn S, Monson R, Schoenbaum S, Stubblefield PG, Ryan KJ. The Association of alcohol consumption with outcome of pregnancy. Am J Public Health. 1983;73:1165-8.

21. McDonald AD, Armstrong BG, Sloan M. Cigarette, alcohol, and coffee consumption and prematurity. Am J Public Health. 1992;82:87-90. 
22. Bell R, Lumley J. Alcohol consumption, cigarette smoking and fetal outcome in Victoria, 1985. Aust N Z J Public Health. 1989;13:484-91.

23. Albertsen $\mathrm{K}$, Andersen AMN, Olsen J, Grønbæk M. Alcohol consumption during pregnancy and the risk of preterm delivery. Am J Epidemiol. 2004;159:155-61

24. Henderson J, Gray R, Brocklehurst P. Systematic review of effects of low-moderate prenatal alcohol exposure on pregnancy outcome. BJOG. 2007;114:243-52.

25. Moss NE. Gender Equity and Sosioeconomic Inequality: a framework for the patterning of women's health. Soc Sci Med. 2002;54:649-61.

26. Delgado H, Lechtig A, Yarbrough C, Martorell R, Klein RE, Irwin M, et al. Maternal Nutrition - Its Effect on Infant Growth and Development and Birthspacing. Hagerstown, MD, USA: Harper and Row; 1977.

27. Nemukula M: Homocysteine, Vitamine B12, B6 and Folate Levels in Alcohol and Non-Alcohol Consumers. Polokwane, Limpopo, South Africa: University of Limpopo; 2001

28. Lassi ZS, Salam RA, Haider BA, Bhutta ZA. Folic acid supplementation during pregnancy for maternal health and pregnancy outcomes. Cochrane Database of Syst Rev. 2013;3:CD006896.

29. Choma SSR, Alberts M, Urdal P. Effect of traditional beer consumption on the iron status of a Rural South African Population. South Afr J Clin Nutr. 2007:20:62-8.

30. Requirements of Vitamine A, Iron, Folate and Vitamine B12. Report of a Joint FAO/WHO Expert Consultation, vol. 23/1988. Rome, Italy: Food and Agriculture Organization; 1988.

31. Siega-Riz AM, Hartzema AG, Turnbull C, Thorp J, McDonald T, Cogswell ME. The effects of prophylactic iron given in prenatal supplements on iron status and birth outcomes: a randomized controlled trial. Am J Obstet Gynecol. 2006:194:512-9.

32. Del Boca FK, Darkes J. The validity of self-reports of alcohol consumption: state of the science and challenges for research. Addiction. 2003:98:1-12

\section{Submit your next manuscript to BioMed Central and take full advantage of:}

- Convenient online submission

- Thorough peer review

- No space constraints or color figure charges

- Immediate publication on acceptance

- Inclusion in PubMed, CAS, Scopus and Google Scholar

- Research which is freely available for redistribution 